\title{
Cerâmica popular: Rio Real - tradição técnica e arte em argila
}

\section{(Popular ceramic: Rio Real - technical tradition and art in clay)}

\author{
A. C. M. Ayres da Silva ${ }^{1}$, A. L. M. Ayres da Silva ${ }^{2}$ \\ ${ }^{1}$ Departamento de Engenharia Minas e de Petróleo da Escola Politécnica da Universidade de São Paulo, Av. \\ Prof. Mello Moraes, 2373, SP 05508-030 \\ ${ }^{2}$ Netzsch AKW Equipamentos e Processos Ltda., Rua Samuel Morse, 120, SP 04576-060 \\ annayres@ig.com.br,luizaayres@ig.com.br
}

\begin{abstract}
Resumo
Este trabalho tem como objetivo principal relacionar a utilização da argila, material de expressão artística e cultural, a aspectos técnicos frequentemente ignorados pelos executores (artesãos e artistas), a partir da análise de técnicas tradicionais de modelagem. Busca, portanto, com um estudo de caso, compreender como a matéria-prima (argila), disponível em Rio Real, BA, influenciou o desenvolvimento espontâneo de uma técnica de modelagem empregada nesta região do Brasil, resultando em uma forma peculiar de expressão artística. Assim, objetiva investigar como as propriedades químicas, tecnológicas e cerâmicas desta argila são importantes na definição das características estéticas do trabalho artístico, na escolha do método de execução em suas diferentes fases. A metodologia abrange pesquisa bibliográfica, visita a campo para coleta de material para análise, caracterização do material com os seguintes ensaios: espectrometria de fluorescência de raios $\mathrm{X}$, difração de raios $\mathrm{X}$, microscopia eletrônica de varredura. Os ensaios cerâmicos: tensão de ruptura à flexão de corpos-de-prova cru a $110^{\circ} \mathrm{C}$ e após queima a $850{ }^{\circ} \mathrm{C}, 950{ }^{\circ} \mathrm{C}$ e $1250{ }^{\circ} \mathrm{C}$, perda-ao-fogo, retração linear, massa específica aparente, porosidade, absorção de água, plasticidade e análise granulométrica.
\end{abstract}

Palavras-chave: cerâmica popular, argila, propriedades da argila.

\begin{abstract}
This paper aims to relate the use of clay, as a material for artistic and cultural expression, to technical aspects usually ignored by artisans and artists, based on analyses of popular and traditional modeling techniques. It searches therefore, understand how the raw material (clay), available for this community artisan from Rio Real, BA, Brazil, has influenced the spontaneous development of a modeling technique used in this Brazilian area, resulting in a peculiar way of artistic expression. It was investigated how the chemical, technological and ceramic properties of this clay are important to define the aesthetic features of artistic work and the choice of the execution method in its different phases. The methodology comprehends bibliographical research; field visit to collect data and clay samples to be analyzed, characterization on lab. The tests were performed for characterization: X-ray diffraction, scanning electron microscopy. The ceramic tests: tensile strength flexural body-of-proof raw at $110^{\circ} \mathrm{C}$ and after thermal treatment at $850{ }^{\circ} \mathrm{C}$, $950{ }^{\circ} \mathrm{C}$ and $1250^{\circ} \mathrm{C}$, loss-to-fire, linear shrinkage, bulk density, porosity, water absorption, plasticity and granulometric analysis. Keywords: popular ceramics, clay, clay properties.
\end{abstract}

\section{INTRODUÇÃO}

Características da jazida para extração de argila e da cerâmica de Rio Real

O trabalho fundamentou-se na análise e registro de técnicas tradicionais de modelagem empregadas pelas artesãs de Rio Real, relacionando-as com as propriedades químicas, tecnológicas e cerâmicas das argilas empregadas com matéria-prima na região. Buscando, portanto, compreender como a matéria-prima (argila) disponível, para esta determinada comunidade artesã, influenciou o desenvolvimento espontâneo da técnica de modelagem empregada, resultando em uma forma peculiar de expressão artística. $\mathrm{O}$ atual município Rio Real localiza-se na porção nordeste do estado da Bahia, limite com o estado do Sergipe (Fig. 1). Conta com uma população de 37.164 habitantes e área de $716,885 \mathrm{~km}^{2}$ [1]. A cerâmica produzida na região é con- siderada muito tradicional, mantendo até hoje suas características técnicas e estilísticas "originais". Foi incluída no Inventário Nacional de Referências Culturais - INRC. Sua produção é exclusivamente feminina (louceiras), uma reminiscência da sociedade indígena. Está concentrada no povoado "Carro Quebrado", aproximadamente a $3 \mathrm{~km}$ do município Rio Real. Trata-se de uma região essencialmente agrícola e bastante carente.

Jazida: A argila é extraída do lago Salgado Grande, o principal barreiro da região.

Preparação da argila: a argila seca é peneirada para retirar impurezas como restos de plantas, depois, acrescentando-se água, é amassada com os pés e por fim com as mãos.

Técnicas de Modelagem, Formas e Decoração: utilização da técnica de roletes, "endanhas" colocados uns sobre os outros, em uma base redonda de argila, unidos com o uso de uma palheta. Colocado o primeiro rolete 


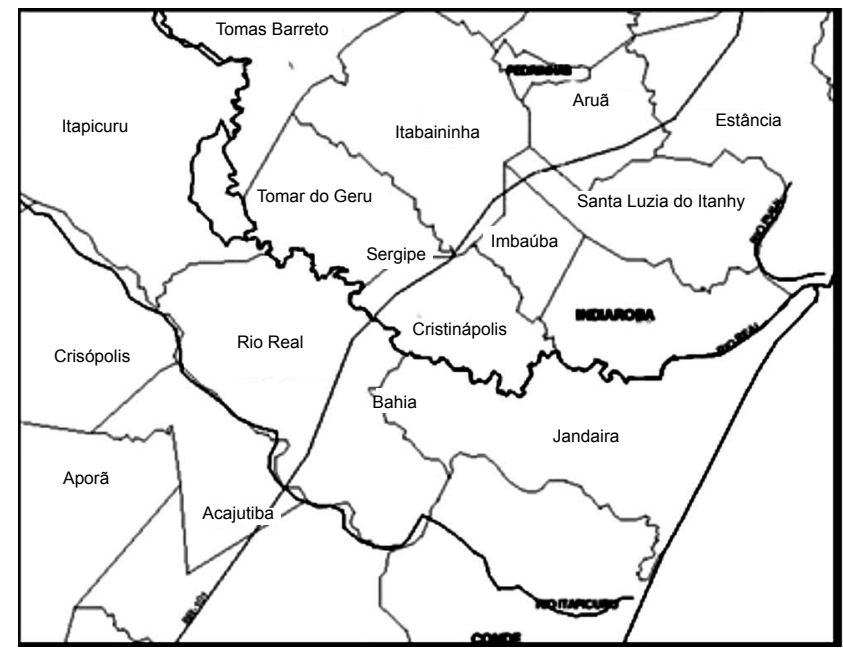

Figura 1: Localização do município de Rio Real e municípios vizinhos [2].

[Figure 1: Location of Rio Real and neighboring municipalities [2].]

espera-se secar um pouco para em seguida sobrepor o segundo e assim por diante. Para colagem de algumas partes do vaso são feitos cortes para uma boa adesão das partes e o alisamento é feito com uma faca. A pintura das peças modeladas em argila branca é feita com engobe de argila vermelha ("Tauá”) obtida numa cerâmica próxima a Rio Real, do qual são passadas muitas demãos. A peça em seguida é polida, raspando-se a semente mucunã (olho-deboi) repetidas vezes até se obter o brilho desejado. Então, é decorada sobre o fundo vermelho, com desenhos feitos em argila clara (branca). Utilizam então, dois engobes,

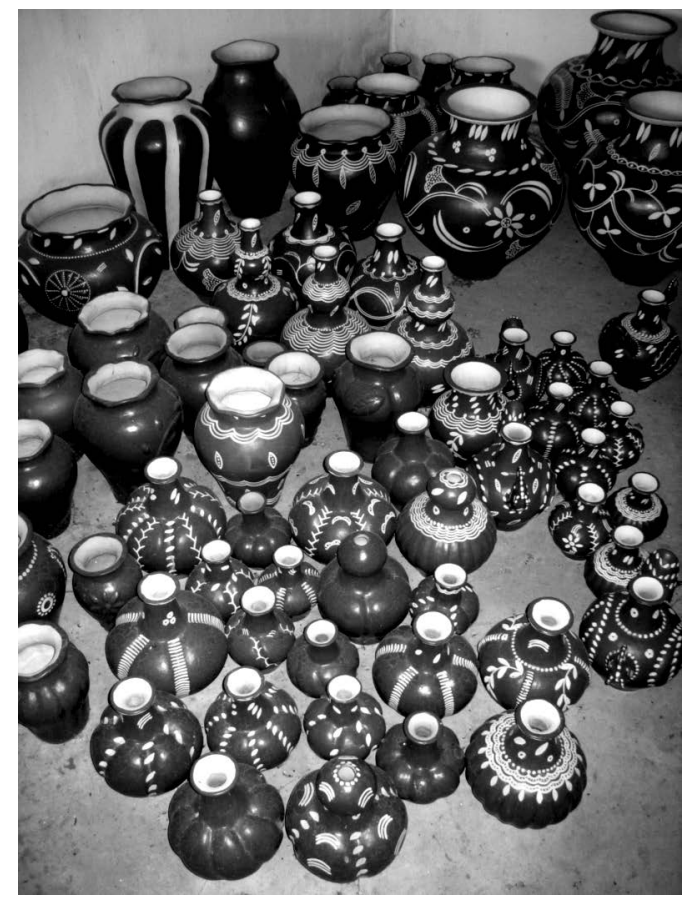

Figura 2: Formas e padrões das peças de Rio Real (fotos: autor). [Figure 2: Shapes and patterns of Rio Real pieces (photos: author).]
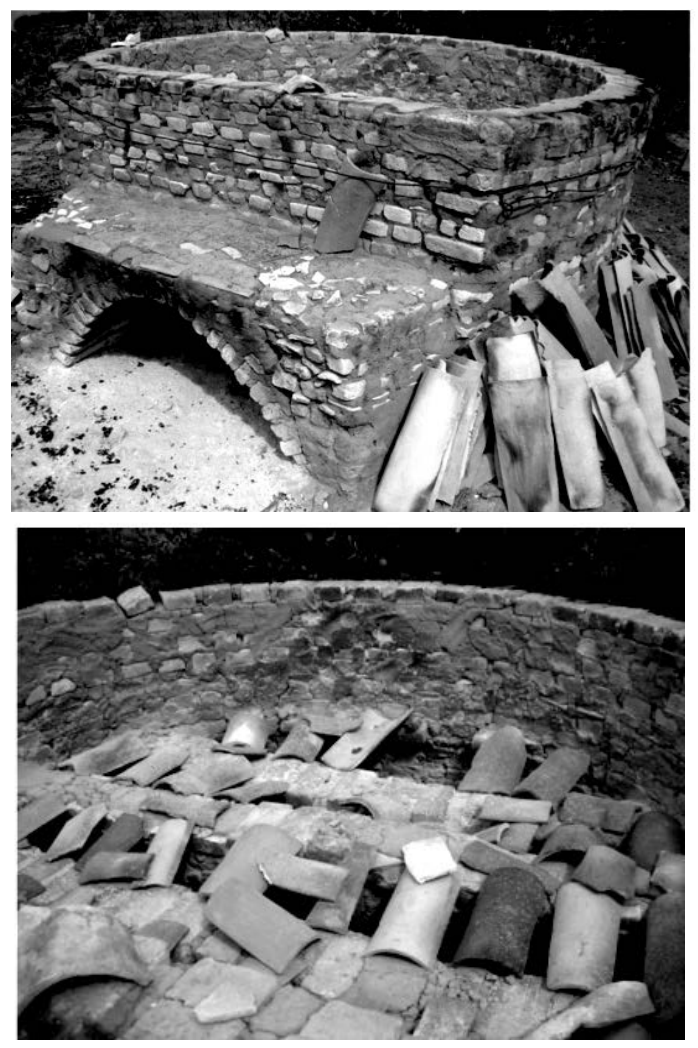

Figura 3: Forno de Dona do Carmo - vista externa e interna (fotos: autor).

[Figure 3: Oven - Dona do Carmo - internal and external views (photos: author)]

o vermelho para banhar a peça e branco para decorá-la. Como "pincel" para os desenhos em branco, usam um pequeno talo de pindoba (Attalea compta) com um pedaço de pano na ponta ("insope"). Os motivos dos famosos "bordados em Tauá" variam desde desenhos geométricos, bicos-de-renda a motivos fitomorfos. Emprega-se também a utilização do alto relevo. As principais peças são: farinheiras e moringas em forma de galinha ou formas de pitanga, grandes potes para água e grandes jarrões e vasos (Fig. 2).

Queima: originalmente a queima era semelhante à técnica tradicional indígena, as artesãs faziam um buraco no chão onde depositavam as peças, cobriam com lenha, e então ateavam fogo, deixando queimar até sentirem que a peça estava pronta. A queima atualmente é feita uma única vez, em um forno a lenha. Caracteriza-se por ser uma queima de baixa temperatura, com duração de 9 a 12 h [3]. O forno é forrado para apoiar as peças e depois coberto com telhas. Os fornos são construídos com tijolos produzidos nas olarias da região, não alcançando temperaturas superiores a $900^{\circ} \mathrm{C}$, isto em função da forma como são construídos.

\section{MATERIAIS E MÉTODOS}

Para a caracterização das amostras de argila foram feitos os seguintes ensaios: espectrometria de fluorescência 
de raios $\mathrm{X}$ com espectrômetro de fluorescência de raios $\mathrm{X}$ seqüencial Axios Advanced PANalytical, difração de raios X com o difratômetro Philips MPD 1880 pelo método do pó. A identificação das fases cristalinas foi obtida por comparação do difratograma com o banco de dados do ICDD - International Centre for Diffraction Data, microscopia eletrônica de varredura com microscópio FEI Quanta 600 FEG e de metalizador para preparo das amostras Coating System Bal-tec MED-020, análise granulométrica com analisador de Partículas Malvern MSS Mastersizer ( 0,05 a $3500 \mu \mathrm{m}$ ), colorimetria com colorímetro MiniScan XE Plus 45/0 SAV (73440) no modo de reflexão.

Já para a análise das propriedades cerâmicas das argilas foram realizados os seguintes ensaios:

Ensaios Cerâmicos: As amostras das argilas coletadas foram nomeadas segundo sua origem e cor de queima: $1 \mathrm{RV}$ - argila de Rio Real vermelha (utilizada somente como engobe); $2 \mathrm{RB}$ - argila de Rio Real branca (utilizada como matéria-prima para modelagem das peças).

Preparação das amostras: as amostras secas ao sol foram destorroadas, moídas com almofariz, depois passaram por peneiras ABNT 25 (24 mesh) e 40 (35 mesh), até se obter um total de $260 \mathrm{~g}$ de cada tipo de argila. Os corpos de prova foram conformados por prensagem de $200 \mathrm{kgf} /$ $\mathrm{cm}^{2}$ em prensa hidráulica Carver 3912, como plaquetas retangulares com as dimensões de $60 \times 20 \times 5 \mathrm{~mm}^{3}$, com aproximadamente $10 \mathrm{~g}$ cada.

Secagem: corpos de prova de cada tipo de argila foram secos na estufa a $110{ }^{\circ} \mathrm{C}$ por $24 \mathrm{~h}$. A determinação do módulo de tensão de ruptura à flexão após secagem e após queima foi em uma prensa Kratos K2000MP de capacidade $2.000 \mathrm{kgf}$.
Queima: a queima nas três temperaturas determinadas $\left(850^{\circ} \mathrm{C}, 950{ }^{\circ} \mathrm{C}\right.$ e $\left.1250^{\circ} \mathrm{C}\right)$ foi realizada em forno Lindberg/ Blue.

Ensaios realizados com amostras secas: umidade de conformação (base seca), retração linear e módulo de tensão de ruptura à flexão. Ensaios realizados com 6 corpos de prova de cada argila [4].

Ensaios realizados com amostras queimadas nas três temperaturas: retração linear de queima, módulo de tensão de ruptura à flexão após queima, absorção de água após queima, porosidade, perda ao fogo e cor. Ensaios também realizados com 6 corpos de prova de cada argila [4].

\section{RESULTADOS}

Abaixo estão discriminados os resultados obtidos nos ensaios.

Análise semiquantitativa por espectrometria de fluorescência de raios X. Resultados em \% de óxidos, normalizados a $100 \%$

\section{Análise Granulométrica}

Tabela II - Resultado da análise granulométrica das amostras das argilas $1 \mathrm{RV}$ e $2 \mathrm{RB}$.

[Table II-Result of particle size analysis of the clay samples $1 R V$ and $2 R B$.

\begin{tabular}{cccc}
\hline Método Malvern & $\mathrm{D} 10(\mu \mathrm{m})$ & $\mathrm{D} 50(\mu \mathrm{m})$ & $\mathrm{D} 90(\mu \mathrm{m})$ \\
\hline 1RV & 1,89 & 6,96 & 36,22 \\
2RB & 2,97 & 11,74 & 38,93 \\
\hline
\end{tabular}

Tabela I - Resultado da análise química das amostras $1 \mathrm{RV}$ e $2 \mathrm{RB}$. [Table I-Chemical analysis result of the samples $1 R V$ and 2RB.]

\begin{tabular}{|c|c|c|c|c|c|}
\hline \multirow{2}{*}{ Óxidos } & \multicolumn{2}{|c|}{ Amostra } & \multirow{2}{*}{ Óxidos } & \multicolumn{2}{|c|}{ Amostra } \\
\hline & $1 \mathrm{RV}$ & $2 \mathrm{RB}$ & & $1 \mathrm{RV}$ & $2 \mathrm{RB}$ \\
\hline $\mathrm{Na}_{2} \mathrm{O}$ & nd & 0,05 & $\mathrm{Fe}_{2} \mathrm{O}_{3}$ & 22,0 & 1,97 \\
\hline $\mathrm{MgO}$ & 0,14 & 0,12 & $\mathrm{CO}_{3} \mathrm{O}_{4}$ & 0,01 & nd \\
\hline $\mathrm{Al}_{2} \mathrm{O}_{3}$ & 21,5 & 19,8 & $\mathrm{NiO}$ & 0,02 & 0,01 \\
\hline $\mathrm{SiO}_{2}$ & 41,1 & 65,6 & $\mathrm{CuO}$ & 0,03 & nd \\
\hline $\mathrm{P}_{2} \mathrm{O}_{5}$ & 0,04 & 0,02 & $\mathrm{ZnO}$ & 0,01 & « \\
\hline $\mathrm{SO}_{3}$ & 0,07 & 0,03 & $\mathrm{Ga}_{2} \mathrm{O}_{3}$ & nd & « \\
\hline $\mathrm{Cl}$ & 0,02 & 0,02 & $\mathrm{Rb}_{2} \mathrm{O}$ & $\ll$ & « \\
\hline $\mathrm{K}_{2} \mathrm{O}$ & 0,09 & 0,12 & $\mathrm{SrO}$ & nd & « \\
\hline $\mathrm{CaO}$ & 0,19 & 0,14 & $\mathrm{Y}_{2} \mathrm{O}_{3}$ & 0,01 & nd \\
\hline $\mathrm{Sc}_{2} \mathrm{O}_{3}$ & 0,01 & nd & $\mathrm{ZrO}_{2}$ & 0,03 & 0,02 \\
\hline $\mathrm{TiO}_{2}$ & 1,46 & 0,96 & $\mathrm{BaO}$ & nd & 0,04 \\
\hline $\mathrm{V}_{2} \mathrm{O}_{5}$ & 0,03 & 0,01 & $\mathrm{PbO}$ & nd & 0,01 \\
\hline $\mathrm{Cr}_{2} \mathrm{O}_{3}$ & 0,09 & 0,01 & $\mathrm{PF}$ & 130 & 111 \\
\hline $\mathrm{MnO}$ & 0,19 & 0,01 & $P \Gamma$ & 15,0 & 11,1 \\
\hline
\end{tabular}

Dados operacionais: $n d$ - elemento não detectado

$"=$ traços (menor que 0,01\%) 
Difração de raios $X$

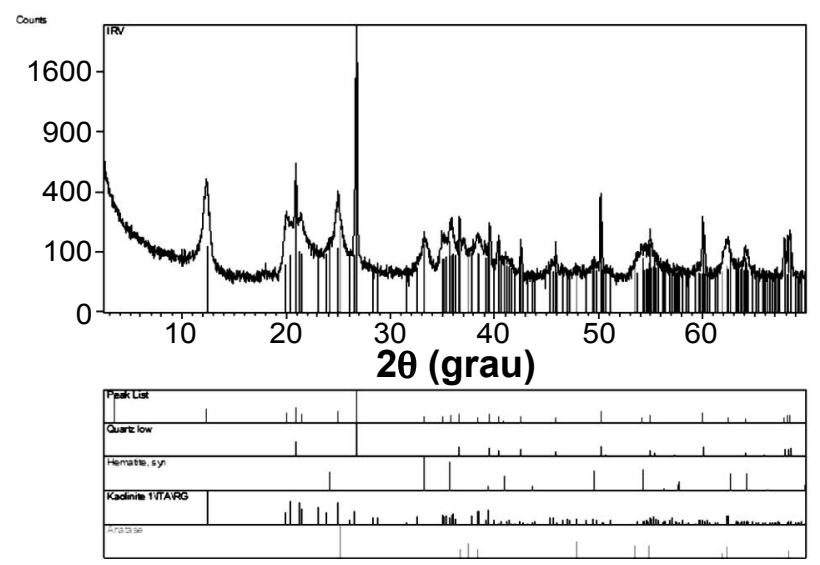

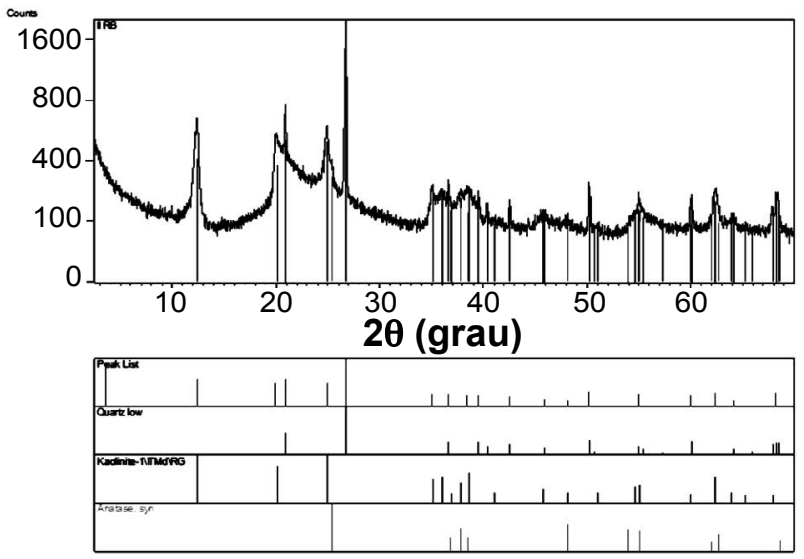

Figura 3: Difratogramas de raios $\mathrm{X}$ - amostras $1 \mathrm{RV}$ e 2RB.

[Figure 3: X-ray diffraction patterns of the clay samples $1 R V$ and $2 R B$.]

Tabela III - Resultados ensaios cerâmicos - amostras secas a $110^{\circ} \mathrm{C}$.

[Table III - Ceramic tests - dry samples, $110^{\circ} \mathrm{C}$.]

\begin{tabular}{cccc}
\hline $\begin{array}{c}\text { Argila seca } \\
110^{\circ} \mathrm{C}\end{array}$ & $\begin{array}{c}\text { Umidade de } \\
\text { moldagem } \\
(\%)\end{array}$ & $\begin{array}{c}\text { Retração } \\
\text { linear } \\
(\%)\end{array}$ & $\begin{array}{c}\text { Modulo de } \\
\text { ruptura } \\
(\mathrm{MPa})\end{array}$ \\
\hline $1 \mathrm{RV}$ & 2,53 & 0,27 & 1,92 \\
$2 \mathrm{RB}$ & 4,25 & 0,26 & 1,28 \\
\hline
\end{tabular}

Tabela IV - Resultados dos ensaios cerâmicos - amostra $2 \mathrm{RB}$ queimada $\left(850^{\circ} \mathrm{C}, 950{ }^{\circ} \mathrm{C}\right.$ e $\left.1250{ }^{\circ} \mathrm{C}\right)$.

[Table IV - Ceramic test-sample $2 R B$ burned $\left(850^{\circ} \mathrm{C}, 950^{\circ} \mathrm{C}\right.$ and $\left.\left.1250{ }^{\circ} \mathrm{C}\right).\right]$

\begin{tabular}{ccccccc}
\hline \multirow{2}{*}{ Amostra 2RB } & $\begin{array}{c}\text { Temperatura } \\
\text { de queima } \\
\left({ }^{\circ} \mathrm{C}\right)\end{array}$ & $\begin{array}{c}\text { Perda ao } \\
\text { fogo } \\
(\%)\end{array}$ & $\begin{array}{c}\text { Retração } \\
\text { linear } \\
(\%)\end{array}$ & $\begin{array}{c}\text { Modulo de } \\
\text { ruptura } \\
(\mathrm{MPa})\end{array}$ & $\begin{array}{c}\text { Absorção de } \\
\text { água } \\
(\%)\end{array}$ & $\begin{array}{c}\text { Porosidade } \\
\text { aparente } \\
(\%)\end{array}$ \\
\cline { 2 - 7 } & 850 & 9,1 & 2,12 & 2,72 & 26,97 & 32,72 \\
& 950 & 10,6 & 3,51 & 4,41 & 26,79 & 31,99 \\
1250 & 11,3 & 15,85 & 14,00 & 7,29 & 9,48 \\
\hline
\end{tabular}

Tabela V - Resultados dos ensaios cerâmicos - amostra $1 \mathrm{RV}$ queimada $\left(850^{\circ} \mathrm{C}, 950{ }^{\circ} \mathrm{C}\right.$ e $\left.1250{ }^{\circ} \mathrm{C}\right)$.

[Table V-Ceramic test results - sample $1 R V$ burned $\left(850^{\circ} \mathrm{C}, 950{ }^{\circ} \mathrm{C}\right.$ and $\left.1250{ }^{\circ} \mathrm{C}\right)$. .]

\begin{tabular}{cccccc}
\hline \multirow{2}{*}{$\begin{array}{c}\text { Temperatura } \\
\text { de queima } \\
\left({ }^{\circ} \mathrm{C}\right)\end{array}$} & $\begin{array}{c}\text { Perda ao } \\
\text { fogo } \\
(\%)\end{array}$ & $\begin{array}{c}\text { Retração } \\
\text { linear } \\
(\%)\end{array}$ & $\begin{array}{c}\text { Modulo de } \\
\text { ruptura } \\
(\mathrm{MPa})\end{array}$ & $\begin{array}{c}\text { Absorção de } \\
\text { água } \\
(\%)\end{array}$ & $\begin{array}{c}\text { Porosidade } \\
\text { aparente } \\
(\%)\end{array}$ \\
\cline { 2 - 7 } & 11,7 & 1,71 & 0,89 & 22,55 & 31,62 \\
950 & 12,9 & 2,61 & 1,48 & 22,65 & 31,08 \\
1250 & 13,3 & 8,87 & 3,21 & 12,04 & 21,00 \\
\hline
\end{tabular}

Tabela VI - Limite de Plasticidade (LP), Limite de Liquidez (LL) e Índice de Plasticidade (IP).

[Table VI - Plastic Limit (PL), Liquid Limit (LL) and Plasticity Index (PI).]

\begin{tabular}{ccc}
\hline Limites de Atterberg & \multicolumn{2}{c}{ Amostras } \\
\hline (\%) & $2 \mathrm{RB}$ & $1 \mathrm{RV}$ \\
LL & 42,9 & 49,6 \\
LP & 30,0 & 33,4 \\
IP & 12,9 & 16,2 \\
\hline
\end{tabular}




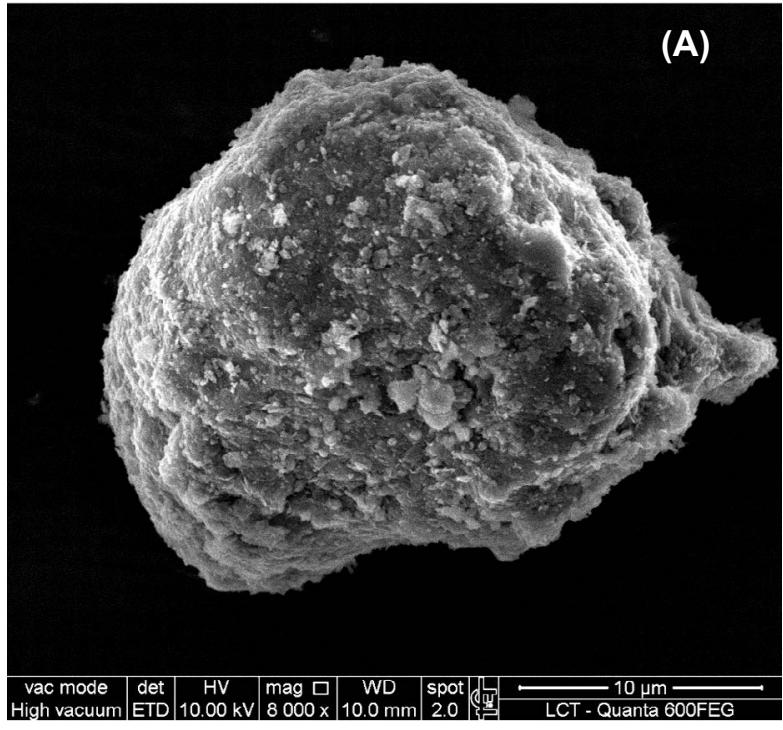

1RV - Caulinita

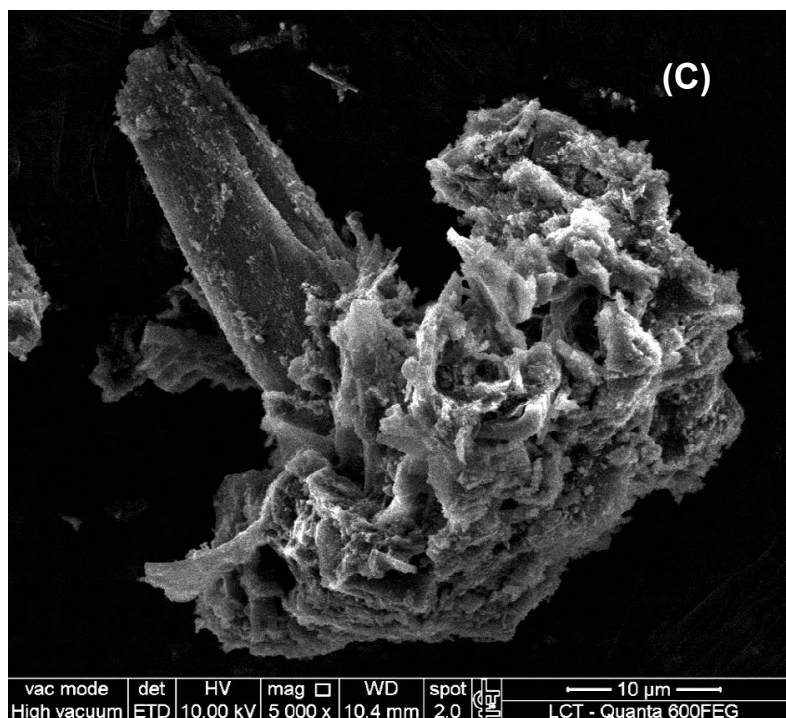

$2 \mathrm{RB}$ - Cristais de quartzo e caulinita

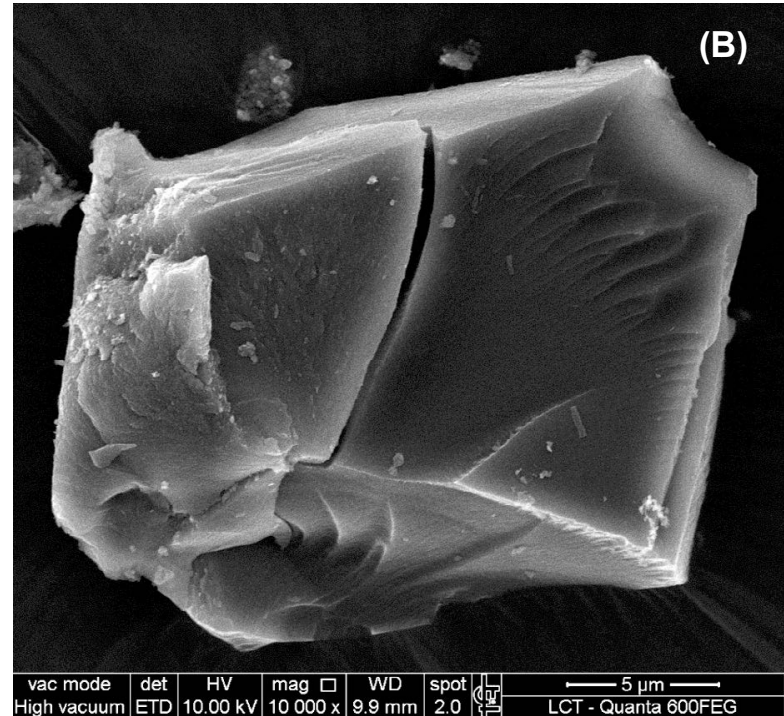

1RV - Quartzo

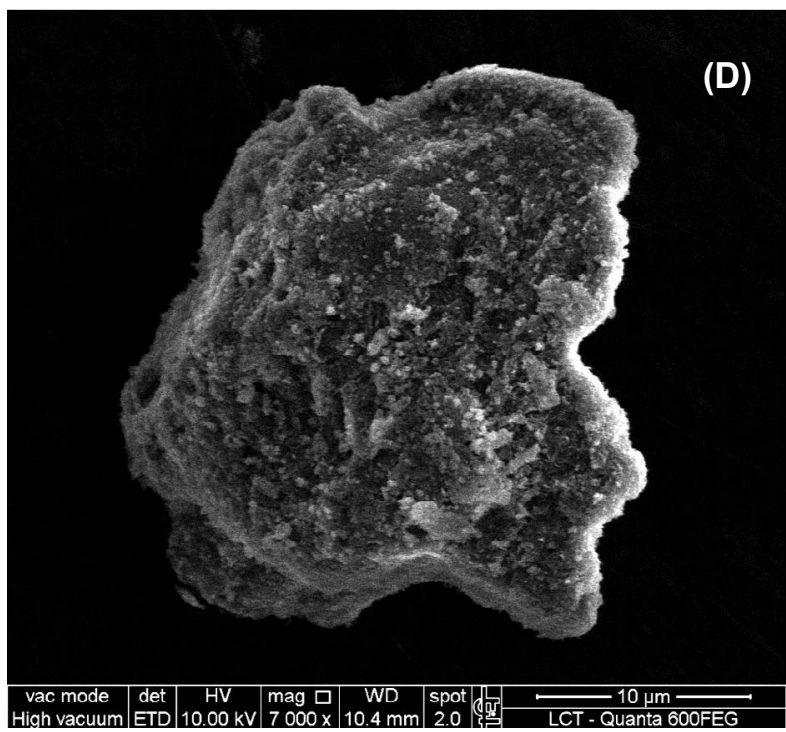

2RB - Caulinita

Figura 4: Micrografias (MEV) das amostras da argila 1RV e 2RB. [Figure 4: SEM micrographs of the clay samples $1 R V$ and 2RB.]

\section{DISCUSSÃO}

Análise Química: a razão $\mathrm{SiO}_{2} / \mathrm{Al}_{2} \mathrm{O}_{3}$ é um parâmetro indicativo da quantidade de argilomineral e quartzo, sendo que 1,18 corresponde a composição teórica da caulinita $(46,5 / 39,5)$. Valores maiores indicam presença de sílica livre na forma de quartzo. Segundo a relação $\mathrm{SiO}_{2} / \mathrm{Al}_{2} \mathrm{O}_{3}$, todas as argilas estudadas apresentam alto teor se sílica, destacando-se em quantidade a argila $2 \mathrm{RB}(3,31 \%)$ e depois $1 \mathrm{RV}(1,91 \%)$. A sílica livre provoca tanto a redução da plasticidade, como baixa retração linear. $\mathrm{O} \mathrm{TiO}_{2} \mathrm{em}$ quantidades baixas, como no caso das amostras analisadas $(1,46 \%-1 \mathrm{RV}$ e $0,96 \%$ - 2RB) indica a origem sedimentar dessas argilas. Segundo Souza Santos, não há alterações nas propriedades tecnológicas, para quantidades inferiores

a $1 \%$, portanto a presença de $0,96 \%$ de titânio na argila $2 \mathrm{RB}$ já indica um comprometimento na cor, deixando o branco acinzentado [4]. A amostra $1 \mathrm{RV}$ apresenta $22 \%$ de $\mathrm{Fe}_{2} \mathrm{O}_{3}$, contrastando bastante da amostra 2RB, com teor de apenas $1,97 \%$ de $\mathrm{Fe}_{2} \mathrm{O}_{3}$. Essa é a principal diferença observada entre as duas argilas. Argilas com altos teores de minerais de ferro promovem fundamentalmente a diminuição da refratariedade e alteração na cor da argila queimada, Souza Santos (1989). Segundo o resultado da colorimetria, a argila $2 \mathrm{RB}$ "branca" foi considerada mesmo, em três temperaturas de queima $\left(850{ }^{\circ} \mathrm{C}, 950{ }^{\circ} \mathrm{C}\right.$, e $\left.1250{ }^{\circ} \mathrm{C}\right)$ sempre "amarelo avermelhado claro". A cor da argila $1 \mathrm{RV}$ foi considerada nas temperaturas $850^{\circ} \mathrm{Ce} \quad 950^{\circ} \mathrm{C}$ como "amarelo avermelhado escuro" e a $1250^{\circ} \mathrm{C}$ como "vermelho amarelado escuro". As amostras $1 R V$ e $2 \mathrm{RB}$ apresentam teores baixos e semelhantes 
quanto ao óxido alcalino terroso $\mathrm{CaO}$ : (1RV $-0,19 \%$ e $2 \mathrm{RB}$ $-0,14 \%)$. O mesmo ocorre quanto ao óxido alcalino terroso $\mathrm{MgO}(1 \mathrm{RV}-0,14 \%$ e $2 \mathrm{RB}-0,12 \%)$. Teores tão baixos não devem influenciar na refratariedade das argilas, mesmo sendo fundentes.

Análise Granulométrica: em função dos resultados de análise granulométrica apresentados na Tabela II, observase que a argila $2 \mathrm{RB}$ apresenta partículas bem maiores.

Difração de raios $X$ : a análise dos difratogramas de raios X para cada uma das argilas demonstra predominância do argilomineral caulinita, do quartzo e anatásio nas duas amostras (Fig. 3). Podem ser consideradas, portanto, argilas cauliníticas, com alto teor de alumina e sílica. Na amostra 1RV destaca-se a hematita, a quantidade de ferro é evidenciada na análise química $\left(22 \%\right.$ de $\left.\mathrm{Fe}_{2} \mathrm{O}_{3}\right)$ (Tabela I).

Microscopia eletrônica de varredura: com o uso do microscópio eletrônico de varredura foi possível observar a morfologia dos minerais constituintes das amostras 1RV e 2RB. Nota-se o arranjo lamelar da caulinita e também o baixo grau de perfeição do seu reticulado cristalino, caracterizando-a como uma caulinita mal cristalizada. Observa-se na Fig. 4 até uma tendência de enrolamento nos bordos das placas de caulinita em virtude da finura de suas placas. Nas micrografias destacam-se também cristais de quartzo, como era esperado em função do alto teor de sílica presente nas duas argilas estudadas.

Ensaios Cerâmicos: os corpos de prova das argilas 1RV e 2RB apresentaram praticamente os mesmos índices de retração linear: $0,27 \%$ e $0,26 \%$ respectivamente (Tabela III). $\mathrm{O}$ que é muito interessante, pois a argila $1 \mathrm{RV}$ é usada como engobe na pintura das peças moldadas a mão com a argila $2 \mathrm{RB}$. Se a diferença de retração linear fosse muito grande não poderíamos conseguir o efeito esperado e a superfície da peça poderia apresentar trincas na secagem à sombra e até se desprender na queima. Isso se verifica também, em função da composição química das argilas, pois, segundo Leach, "quanto mais semelhante for a composição da argila da peça e da argila utilizada para preparação dos engobes melhor a aderência do engobe. Se a contração do engobe for maior que a da peça, os engobes podem se desprender da peça durante a queima." [5]. Apesar das composições químicas muito semelhantes (excetuando-se o alto percentual de $\mathrm{Fe}_{2} \mathrm{O}_{3}$ da $1 \mathrm{RV}$ ), as argilas $1 \mathrm{RV}$ e $2 \mathrm{RB}$ apresentaram grandes variações em suas propriedades, as quais foram verificadas pelos ensaios mecânicos. Daí verifica-se a importância, já explicitada por Grim, da realização de ensaios variados para determinação das propriedades das argilas [6]. Isto porque, antigamente, “... análises químicas eram a única ferramenta e não completamente satisfatória, pois logo se tornou óbvio que, argilas de composição química muito diferentes poderiam ter as mesmas propriedades cerâmicas, e argilas de mesma composição química poderiam ter propriedades muito diferentes". Os valores apresentados na Tabela V mostram que a argila vermelha de Rio Real 1RV, usada só como engobe, não apresenta qualquer possibilidade de ser usada na confecção de vasos, pois seu módulo de ruptura é muito baixo: $0,89 \mathrm{MPa}$ a $850^{\circ} \mathrm{C}$; que deve ser a temperatura máxima atingida pelo forno das artesãs. E mesmo a $950{ }^{\circ} \mathrm{C}$, chega a $1,48 \mathrm{MPa}$ e $3,21 \mathrm{MPa}$ a $1250^{\circ} \mathrm{C}$. Nota-se uma enorme discrepância se comparados com os valores obtidos para argila clara $2 \mathrm{RB}-2,72 \mathrm{MPa}$ a $850{ }^{\circ} \mathrm{C} ; 4,41 \mathrm{MPa}$ a $950{ }^{\circ} \mathrm{C}$ e $14,00 \mathrm{MPa}$ a $1250^{\circ} \mathrm{C}$. Isto comprova a observação das artesãs de Rio Real, que insistiam em dizer que a argila vermelha realmente não servia para modelagem de vasos, somente como "tinta".

Os valores obtidos para absorção de água de $1 \mathrm{RV}$ e 2RB estão no limite dos valores da argila padrão para cerâmica vermelha a $950{ }^{\circ} \mathrm{C}$ (faixa de 2 a $25 \%$ ). Para $1250^{\circ} \mathrm{C}$, eles se encontram dentro da faixa (de 1 a $30 \%$ ) [4]. A argila $2 \mathrm{RB}$ apresentou os valores praticamente iguais para as temperaturas mais baixas: $26,97 \%$ a $850{ }^{\circ} \mathrm{C}$; $26,79 \%$ a $950{ }^{\circ} \mathrm{C}$ e $7,29 \%$ a $1250{ }^{\circ} \mathrm{C}$ (Tabela IV). A argila $1 \mathrm{RV}$ apresentou $22,55 \%$ a $850{ }^{\circ} \mathrm{C} ; 22,65 \%$ a $950{ }^{\circ} \mathrm{C}$ e uma absorção maior para $1250{ }^{\circ} \mathrm{C}$ de $12,04 \%$ (Tabela V).

Quanto à plasticidade, a argila $1 \mathrm{RV}$ apresentou resultado como altamente plástica ( $\mathrm{IP}=16,2 \%)$ enquanto a argila $2 \mathrm{RB}$ apresentou resultado como medianamente plástica ( $\mathrm{IP}=$ $12,9 \%$ ) (Tabela VI), valores coerentes com o percentual de quartzo existente nas amostas $[7,8]$.

Polimento: tecnicamente o que ocorre com esta prática, segundo Norton e que foi observado no trabalho, é a formação $\%$ de uma camada superficial de placas de argilominerais assentadas paralelamente à superfície [9]. Mesmo a queima não destrói a orientação das placas, permanecendo o brilho.

Outro aspecto curioso da utilização do engobe em Rio Real, é que a cobertura externa das peças com o engobe é total. $\mathrm{O}$ vaso que seria originalmente branco torna-se vermelho com apenas ornamentos em branco. Interessante especular o porquê desta escolha. Talvez, se deva à beleza do brilho obtido com o polimento da argila escura. Tal efeito não seria observado com tamanha intensidade se a argila fosse clara. $\mathrm{O}$ vermelho escuro da argila $1 \mathrm{RV}$ é característico da região. É muito fácil distinguir o vermelho de Rio Real, de peças mais claras, por exemplo, de Maragogipinho [10]. Observa-se que além da cor e apesar da ornamentação semelhante, a forma de produção em Maragogipinho é diferente. Utiliza-se o torno de pedal e os vasos também são decorados com engobe branco para a ornamentação e vermelho para o fundo, mas por dentro do vaso é possível ver que a argila original é de cor creme.

\section{CONCLUSÕES}

A utilização das argilas estudadas pelas artesãs de Rio Real é feita de forma muito adequada, segundo as tradições locais e recursos técnicos disponíveis na região. Há grande relação entre o tipo de argila disponível e as características da peça produzida. Não há qualquer intenção do presente estudo em influenciar na concepção destes trabalhos que, apesar da extrema simplicidade com que são elaborados, conseguem surpreender pela qualidade estética obtida. O domínio da técnica de construção e polimento é digno de ressalto. E a beleza das formas e tamanho alcançado das peças também é impressionante. Há um completo domínio das 
etapas de execução, seguidas a risca como receita, e apesar do desconhecimento das causas para tais diretrizes, verificam-se completamente verdadeiras em sua função técnica. Obviamente que, a resistência mecânica desta cerâmica poderia ser muito superior, se o forno atingisse alta temperatura. Entretanto, não é esse o enfoque da pesquisa, não se pretende sugerir "melhorias" que poderiam alterar o resultado do trabalho desenvolvido ao longo de tantas décadas, ou poderiam causar um desvirtuamento do sentido do trabalho. Para a utilização desejada, os resultados são muito satisfatórios.

\section{AGRADECIMENTOS}

À CAPES pela bolsa de incentivo à pesquisa. Agradecemos também ao programa de Pós-Graduação do Departamento de Engenharia Minas e de Petróleo da Escola Politécnica da Universidade de São Paulo, assim como ao Laboratório de Caracterização Tecnológica, ao Laboratório de Processos Cerâmicos e ao Laboratório de Matérias Primas Particuladas e Sólidos Não-Metálicos da Escola Politécnica da Universidade de São Paulo.

\section{REFERÊNCIAS}

[1] Brasil. Instituto Brasileiro de Geografia e Estatística, Censo
2010, Disponível em: <http://www.censo2010.ibge.gov.br/ amostra/> acesso em: 02 de maio (2013).

[2] Brasil. Instituto Brasileiro de Geografia e Estatística, Mapa de Dados Geodésicos, 2005, Sem escala, Disponível em: $<$ http://mapas.ibge.gov.br/solos/viewer.htm> acesso em: $13 \mathrm{de}$ julho (2007).

[3] J. F. Chiti, Hornos Cerâmicos, Condorhuasi, Buenos Aires (1992).

[4] P. Souza Santos, "Ciência e tecnologia de argilas", Edgard Blucher, S. Paulo, SP (1989).

[5] B. Leach, Le Livre du potier, Dessain et Tobra, Paris (1973).

[6] R. E. Grim, "Applied Clay Mineralogy", McGraw-Hill Book Company, New York, EUA (1962).

[7] Associação Brasileira de Normas Técnicas - NBR 6458, "Solo, determinação do limite de liquidez, método de ensaio", Rio de Janeiro, RJ (1984).

[8] Associação Brasileira de Normas Técnicas - NBR 7180, "Solo, determinação do limite de plasticidade, método de ensaio, Rio de Janeiro, RJ (1984).

[9] F. H. Norton, "Introdução à tecnologia cerâmica", Edgard Blucher, S. Paulo, SP (1973).

[10] C. de C. Machado, O barro na arte popular brasileira, Lídio Ferreira Junior Artes Gráfica e Editora, Rio de Janeiro, RJ (1977).

(Rec. 04/05/2013, Rev. 28/08/2013, Ac. 07/09/2013) 